\title{
Occult celiac disease associated with lymphocytic sclerosing cholangitis
}

\author{
HUGH J FREEMAN MD, WC PETER KWAN MD
}

HJ FREEMAN, WCP KWAN. Occult celiac disease associated with lymphocytic sclerosing cholangitis. Can J Gastroenterol 1994;8(4):249-252. A 60-yearold male with dermatitis herpetiformis and a previously treated lymphoma involving an inguinal lymph node developed abnormal liver chemistry tests. Because of intermittent diarrhea, additional studies revealed lymphocytic colitis and occult celiac disease that responded to a gluten-free diet. A liver biopsy done to explore persistently abnormal liver chemistry tests showed a portal tract-centred inflammatory process characterized by biliary ductal proliferation, epithelial lymphocytosis and concentric lamellar fibrosis. Quantitation of immunoglobulins was normal and antimitochondrial antibodies were negative. Retrograde cholangiograms showed radiological features typical of primary sclerosing cholangitis. The epithelial lymphocytosis reported in gastric, small and large intestinal mucosa of some patients with celiac disease may also be present in the biliary ductal columnar epithelium. This report provides additional evidence that celiac disease may be a far more extensive parhological process.

Key Words: Celiac disease, Epithelial lymphocytosis, Gluten-sensitive enteropathy, Inflammatory bowel disease, Liver disease, Lymphoma, Sclerosing cholangitis

\section{Maladie coeliaque occulte associée à une cholangite sclérosante lymphocytaire}

RÉSUMÉ : Un homme de 60 ans atteint d'une maladie de Duhring Brocq et d'un lymphome inguinal ayant déjà été traité, a commencé à présenter des résultats d'enzymes hépatiques anormaux. À cause d'une diarrhée intermittente, d'autres examens ont été effectués et ont révélé une colite lymphocytaire et une maladie coeliaque occulte qui ont répondu à une alimentation sans gluten. Une biopsie hépatique effectuée pour déterminer la cause de la persistance des résultats d'analyses anormaux a démontré un processus inflammatoire centré au continued on next page

Department of Medicine (Gastroenterology), University Hospital and University of British Columbia, Vancouver, British Columbia

Correspondence and reprints: Dr Hugh Freeman, ACU F-137, University Hospital (UBC site), 2211 Wesbrook Mall, Vancouver, British Columbia V6T IW5. Telephone (604)

822.7216

Received for publication October 19, 1993. Accepted January 20, 1994
$\mathrm{P}$ REVIOUS REPORTS HAVE DESCRIBED hepatobiliary tract abnormalities in celiac disease, including chronic cholestatic syndromes (1-3). Indeed, the coexistence of celiac disease and primary biliary cirrhosis is already well described in over 20 patients, including previous reports from two different Canadian teaching hospitals $(4,5)$. Perhaps less well appreciated are the very rare reports of primary sclerosing cholangitis associated with celiac disease $(3,6)$ or lymphoma $(7)$, a condition also known to occur with increased frequency in patients with celiac disease $(8,9)$. Weight loss, malabsorption, bone disease, steatorrhea and elevated alkaline phosphatase activities may be seen as common features in both celiac disease and either of these hepatobiliary tract disorders so that at an early stage of their coexistence, diagnosis of one or the other condition may be missed.

The pathological features in the small intestine of celiac disease are well known. These include blunting of the small intestinal mucosal villi, expansion of the lamina propria by lymphocytes and plasma cells, crypt hyperplasia and marked infiltration of the villous epithelium by lymphocytes with accompanying epithelial cell vacuolization and flattening (10). These in- 
niveau du système porte et caractérisé par une prolifération au niveau des canaux biliaires, une lymphocytose épithéliale et une fibrose lamellaire concentrique. Le dosage des immunoglobulines s'est révélé normal et les anticorps anti-mitochondries négatifs. Les cholangiographies rétrogrades ont révélé des signes radiologiques typiques d'une cholangite sclérosante primaire. La lymphocytose épithéliale observée dans les muqueuses de l'estomac, du petite intestin et du gros intestin de certains patients atteints de maladie coeliaque peut également être présente dans l'épithélium colummellaire des canaux biliaires. Ce rapport procure d'autres preuves à l'effet que la maladie coeliaque peut être un processus pathologique beaucoup plus invasif.

flammatory changes have generally been described in the duodenum and jejunum (11) as well as ileum (12) of patients with celiac disease. In addition, lymphocytosis involving the rectal surface epithelium in patients with celiac disease has been reported (13. 15), as well as a distinctive form of inflammatory change in gastric biopsies, previously described as lymphocytic gastritis (16). Because of these observations in patients with celiac disease, it has been suggested that the histological lesions of epithelial lymphocytosis may have a wide degree of distribution within the gastrointestinal tract (16). The present report describes a patient with dermatitis herpetiformis and lymphoma leading to a diagnosis of occult celiac disease, a previously well studied relationship (17,18), along with an associated lymphocytic colitis (15). In this patient, however, a rather unique constellation of findings were also present including classical laboratory and radiological changes of primary sclerosing cholangitis associated with a portal tract centred primarily lymphocytic inflammatory process.

\section{CASE PRESENTATION}

A 60-year old male was referred in June 1992 for further evaluation of abnormal liver chemistry tests and diarrhea for at least one year. In 1970, dermatitis herpetiformis was diagnosed; he was treated with intermittent dapsone. In 1976, an enlarged right inguinal lymph node was removed; a localized nodal lymphoma was detected and he was treated with chemotherapy and radiotherapy. No recurrent lymphoma was seen during follow-up at the British Columbia Cancer Agency in Vancouver. In May 1991, however, abnormal serum chemistry tests were first seen: alkaline phosphatase, 313 IU/L (normal 29 to 133); alanine aminotransferase, 61 IU/L (normal 7 to 35 ); and aspartate aminotransferase, 67 IU/L (normal 5 to 52). Because of diarrhea (one to four semiformed or loose stools per day), barium radiographs of the upper gastrointestinal tract were done in August 1991. These were normal. An abdominal ultrasound was also normal. Serum chemistry tests were repeated in March 1992 (alkaline phosphatase, 417 IU/L; aspartate aminotransferase, 85 IU/L) and May 1992 (alkaline phosphatase $555 \mathrm{IU} / \mathrm{L}$; aspartate aminotransferase, $124 \mathrm{IU} / \mathrm{L})$.

At the patient's initial review at University Hospital in Vancouver, British Columbia, in June 1992, physical examination was normal. There was no lymphadenopathy and his liver and spleen were not enlarged. There were no peripheral stigmata of chronic liver disease. Laboratory investigations revealed: hemoglobin, 118 (normal 140 to $180 \mathrm{~g} / \mathrm{L}$ ); white blood cell count $4.4 \times 10^{9}$ (normal 4.0 to $11.0 \times 10^{9}$ ); and normal serum iron, iron binding capacity, ferritin, carotene, folic acid and vitamin $B_{12}$. A bone marrow aspirate showed iron but no lymphoma. Upper gastrointestinal endoscopic evaluation in June 1992 was normal. There were no varices and the stomach and small intestine were macroscopically normal. Small bowel biopsies, however, showed a severe 'flat' lesion with crypt hyperplastic villous atrophy characteristic of celiac disease. Gastric biopsies were normal with no lymphocytic gastritis (16). Flexible sigmoidoscopy was normal but a colonic biopsy showed features of epithelial lymphocytosis (15). Serum chemistry tests were more ab- normal (alkaline phosphatase, 630 IU/L; aspartate aminotransferase, 173 IU/L). Antinuclear and antimitochondrial antibodies were negative. Immunoglobulin G, A and M quantitation was normal. Fecal cultures and parasite examinations were negative. Abdominal ultrasound, abdominal and pelvic computed tomography scans were normal; lymphadenopathy was not detected. Percutaneous needle liver biopsy (Figures 1,2) revealed normal liver lobules with bile-duct centred inflammatory change, especially with lymphocytic infiltrates. The limiting plates were intact and there was no lobular inflammation. Focal damage to reactive bile duct epithelium with bile duc tular proliferation was present. Larger portal tracts showed inflammation with some fibrosis present in a concentric lamellar arrangement; severe reactive atypia of bile duct epithelial cells was also present. Lymphoma was not present. Following liver biopsy, a glutenfree diet was initiated. By July 1992, his bowel habit was normal with one formed stool daily. Serum chemistry tests had improved: alkaline phosphatase, $465 \mathrm{IU} / \mathrm{L}$; and aspartate aminotransferase, 168 IU/L. Endoscopic retrograde cholangiography (Figure 3), however, showed multiple stenoses within the intrahepatic biliary tree associated with areas of proximal dilatation. A long tubular fixed narrowing with irregular margins extended throughout the length of the common bile duct but contrast was seen to flow into the duodenum. The appearances suggested sclerosing cholangitis involving both the intrahepatic and extrahepatic biliary tree. A duodenal biopsy done at the time of the cholangiogram showed histological improvement with reappearance of villi. After introduction of the gluten-free diet, serum chemistry tests in November 1992 (alkaline phosphatase, $287 \mathrm{IU} / \mathrm{L}$; aspartate aminotransferase, $117 \mathrm{IU} / \mathrm{L}$; alanine aminotransferase, 93 IU/L) and March 1993 (alkaline phosphatase, 224 IU/L; aspartate aminotransferase, $51 \mathrm{IU} / \mathrm{L}_{\text {i }}$ alanine aminotransferase, 53 IU/L) were improved but not normal; an ab. dominal ultrasound repeated in January 1993 was normal. 


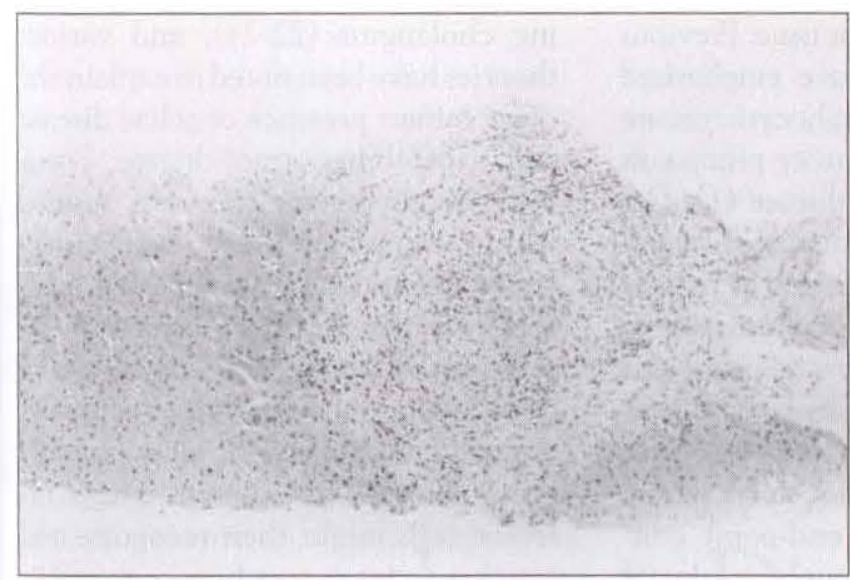

Figure 1) Liver biopsy showing portal tract centred inflammatory process with lymphocytes and concentric lamellar fibrosis (hematoxylin and eosin, $x 73$ )

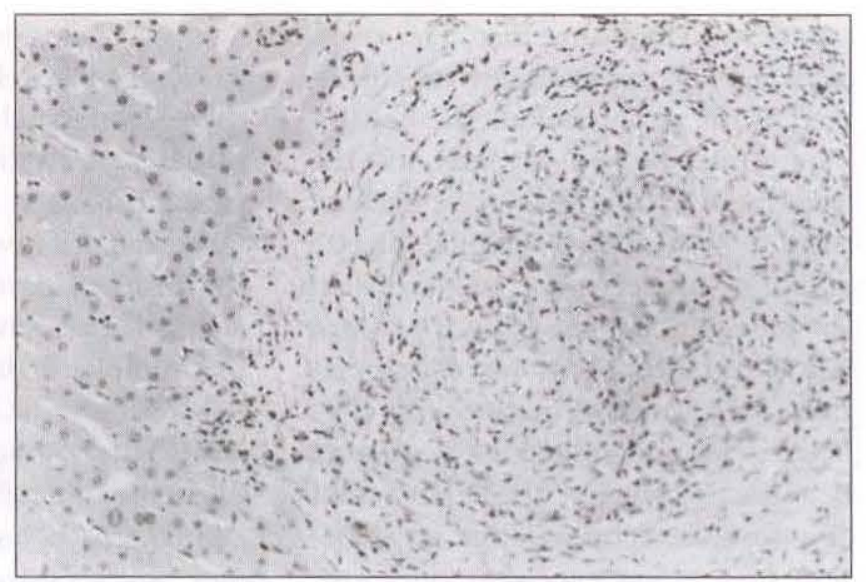

Figure 2) Liver biopsy shouing higher power view of portal tract from Figure 1. Reactive biliary ductal cells are present with predominately lymphocytic infiltrate in the epithelium. In periductal zone, a more dense concentric lamellar fibrosis is present (hematoxylin and eosin, x147)

\section{DISCUSSION}

The presented patient had histologically defined occult celiac disease that was preceded by a long-standing history of dermatitis herpetiformis and a successfully treated lymphoma, a relationship previously described elsewhere (17). Studies in this patient, however, also revealed the presence of lymphocytic colitis (15) and an antimitochondrial antibody negative form of chronic cholestatic liver disease. Further investigations showed a bile duct centred inflammatory process characterized by fibrosis, a predominance of lymphocytes in duct epithelium and cholangiographic features typical of primary sclerosing cholangitis involving the intrahepatic and extrahepatic bile ducts. A number of hepatobiliary tract disorders have been recorded in celiac disease including cholestatic liver diseases such as primary biliary cirrhosis $(4,5)$. Although a common immunological basis may be present, extensive studies to date have failed to identify a common genetic predisposition or common immunological alteration in celiac disease and primary biliary cirrhosis (5). Changes of primary sclerosing cholangitis have been only very rarely recorded in patients with celiac disease $(3,6)$, and the precise relationship between celiac disease and primary sclerosing cholangitis has never been systematically explored (19). Either small bowel biopsy studies of patients with primary sclerosing cholangitis or

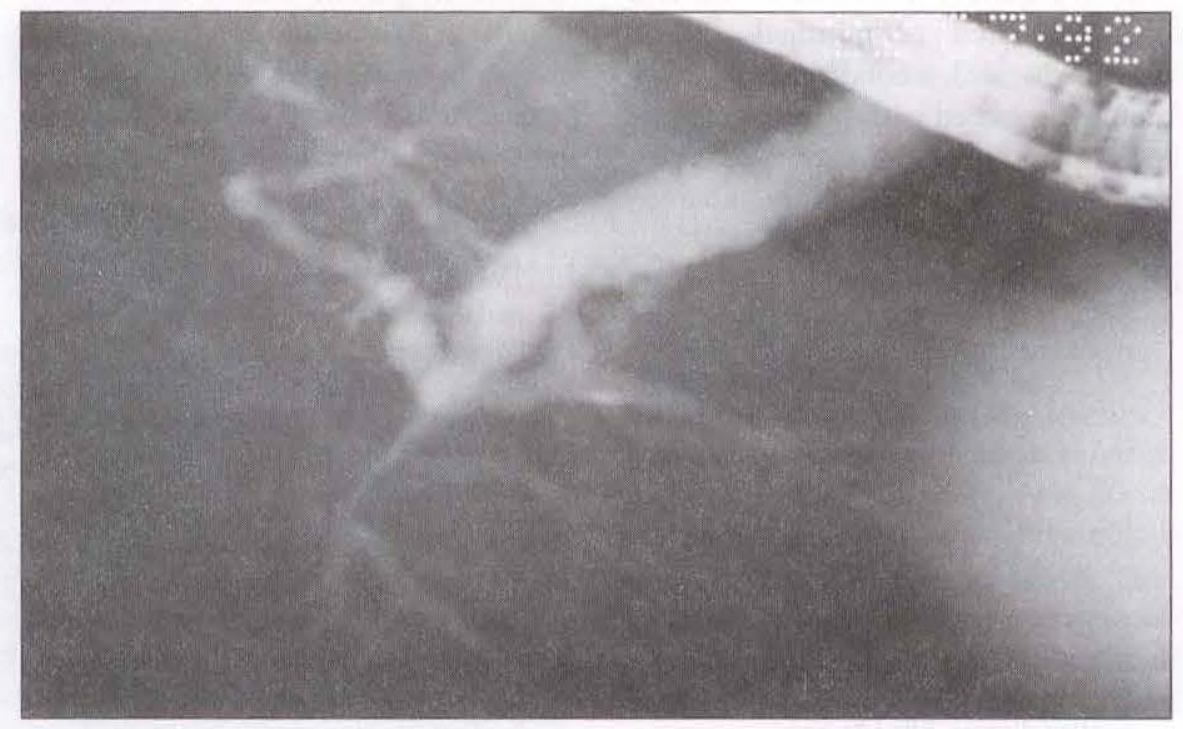

Figure 3) Cholangiogram showing intrahepatic and extrahepatic ductal changes typical of primary sclerosing cholangitis

cholangiographic studies of patients with celiac disease are needed to define this potentially intriguing relationship more precisely. As in celiac disease, many patients with primary sclerosing cholangitis are asymptomatic. Indeed, as is well known in celiac disease, our patient had only limited symptoms despite histological detection of both small and large intestinal disease as well as eventual cholangiographic documentation of rather extensive intrahepatic and extrahepatic radiological changes. These findings further emphasize that biliary tract epithelial changes may be more frequent in celiac disease than is appreciated.
Additional studies are needed to elucidate the natural history of the biliary tract abnormalities in celiac dis. ease and possible biliary tract responses in these patients to a gluten-free diet. Although at least two previous studies indicated that abnormal liver chemistry tests (ie, aspartate aminotransferase, alanine aminotransferase, alkaline phosphatase activities) in celiac disease patients with various forms of hepatobiliary disease improve with gluten restriction $(2,3)$ - as was apparent in this present patient with sclerosing cholangitis $-i$ it is premature to suggest that these improved blood tests were indicative of a convincing biliary tract re- 
sponse to a gluten-free diet. The origin of alkaline phosphatase activities measured in the serum include the hepatobiliary tract as well as bone and the intestine as possible sources; each of these may be altered in celiac disease after introduction of a gluten-free diet. In an earlier report from the Mayo Clinic exploring this novel association with primary sclerosing cholangitis (6), improvement in the celiac disease, but not the biliary tract disease, was recorded after introduction of a gluten-free diet. Unfortunately, in that report, two of the three recorded patients with celiac disease also apparently had concomitant chronic ulcerative colitis (ie, one with 'inactive' quiescent colonic disease and one with 'mild' or 'minimal change' colonic disease), a condition also commonly associated with primary sclerosing cholangitis. Even extensive histological studies may not be able to

\section{REFERENCES}

1. Pollock DJ. The liver in coeliac disease. Histopathology 1977;1:421-30.

2. Hagander B, Brandt L, Sjolund K, Berg NO, Norden A, Stenstam M. Hepatic injury in adult coeliac disease. Lancet 1977;ii:270-2.

3. Jacobsen MB, Fausa O, Elgjo K, Schrumpf E. Hepatic lesions in adult coeliac disease. Scand J Gastroenterol 1990;25:656-62.

4. Iliffe GD, Owen DA. An association between primary biliary cirrhosis and coeliac disease. Dig Dis Sci 1979;24:802-6.

5. Freeman $\mathrm{HJ}$. Celiac disease associated with primary biliary cirrhosis in a Coast Salish native. Can J Gastroenterol 1994;8:105-7.

6. Hay JE, Wiesner RH, Shorter RG, LaRusso NF, Baldus WP. Primary sclerosing cholangitis and celiac disease. A novel association. Ann Intern Med 1988;109:713-7.

7. Alpert LI, Jindrak K. Idiopathic retroperitoneal fibrosis and sclerosing cholangitis associated with a reticulum cell sarcoma. Gastroenterology 1972;62:111-7.

8. Harris OD, Cooke WT, Thompson H, Waterhouse JAH. Malignancy in adult coeliac disease and idiopathic steatorrhea. Am J Med 1967:42:899-912.

9. Logan RFA, Rifkind EA, Turner ID, Ferguson A. Mortality in celiac disease. Gastroenterology 1989;97:265-71. address conclusively this issue. Previous pathological studies have emphasized the predominately lymphocytic nature of the portal inflammatory process in celiac associated liver disease (1). Detailed quantitative studies of intraepithelial lymphocyte numbers in treated celiac disease have shown a persistent elevation in the intestine despite a gluten-free diet $(20,21)$. Thus, the biliary tract response to a gluten-free diet might be difficult to document if the defining pathological end-point consists of lymphocyte counts in ductal epithelium. Increased clinical awareness of this 'more than chance' (19) association of sclerosing cholangitis with celiac disease, however, may eventually permit a more detailed exploration of a possible biliary response to gluten restriction.

Previous studies have documented a wide array of immunological abnormalities in celiac disease as well as scleros-

10. Dobbins WO. Small bowel biopsy in malabsorptive states. In: Norris HT, ed. Pathology of the Colon, Small Intestine and Anus. New York: Churchill Livingstone, 1986:121-65.

11. Rubin CE, Brandborg LL, Phelps PC, Taylor H. Studies of celiac disease. Part 1. The apparent identical and specific nature of the duodenal and proximal jejunal lesion in celiac disease and idiopathic sprue. Gastroenterology 1960;38:28-49.

12. Brow J, Parker F, Weinstein WM, Rubin CE. The small intestinal mucosa in dermatitis herpetiformis. Part 1. Severity and distribution of the small intestinal lesion and associated malabsorption. Gastroenterology 1971;60:355-62.

13. Austin L, Dobbins W. Studies of the rectal mucosa in celiac sprue: the intraepithelial lymphocyte. Gut 1988;29:200-5.

14. Dobbins W, Rubin C. Studies of the rectal mucosa in celiac sprue. Gastroenterology 1964;47:471-9.

15. Wolber R, Owen D, Freeman H. Colonic lymphocytosis in patients with celiac sprue. Hum Pathol 1990;21:1092-6.

16. Wolber R, Owen D, DelBuono L, Appelman H, Freeman H. Lymphocytic gastritis in patients with celiac sprue or spruelike intestinal disease. Gastroenterology 1990;98:310-5.

17. Freeman HJ, Weinstein WM, Shnitka TK, Piercey JR, Wensel RH. Primary ing cholangitis (22-24), and various theories have been noted to explain the concomitant presence of celiac disease and hepatobiliary tract disease. Possibly, immune complexes are formed with a common antigenic basis resulting in tissue damage; no specific antigen, however, has been detected. $\mathrm{Al}$ ternatively, diminished suppressor T cell function might permit effector $\mathrm{cy}$ totoxic lymphocytes to alter a modifying antigen, like gluten. These effector cells might then recognize and attack a patient's own histocompatibility antigens, such as human leukocyte antigen B- 8 and deoxyribose- 3 phenotypes recognized in high incidence in both diseases (19), and possibly present in high concentrations in biliary and intestinal epithelial cells. More immunological studies are needed to elucidate further this intriguing relationship between celiac disease and lymphocytic sclerosing cholangitis.

abdominal lymphoma. Presenting manifestation of celiac sprue or complicating dermatitis herpetiformis. Am J Med 1977;63:585-94.

18. Freeman HJ, Chiu BK. Multifocal small bowel lymphoma and latent celiac sprue. Gastroenterology 1986;90:1992-7.

19. Schrumpf E. Association of primary sclerosing cholangitis and celiac disease: fact or fancy? Hepatology 1989;6:1020-1.

20. Ferguson A, Murray D. Quantitation of intraepithelial lymphocytes in human jejunum. Gut 1971;12:988-94.

21. Holmes GKT, Asquith P, Stokes PL. Cellular infilitrate of jejunal biopsies in adult coeliac disease in relation to gluten withdrawal. Gut 1974;15:278-83.

22. McFarlane IG, Wojcicka BM, Tsantoulas DC, Portmann BC, Eddleston AL, Williams R. Leukocyte migration inhibition in response to biliary antigens in primary biliary cirrhosis, sclerosing cholangitis, and other chronic liver diseases. Gastroenterology 1979;76:1333-40.

23. Bodenheimer HC, LaRusso NF, Thayer WR, Charland C, Staples PJ, Ludwig J. Elevated circulating immune complexes in primary sclerosing cholangitis. Hepatology 1983;3:150-4.

24. Minuk GY, Angus M, Brickman CM. Abnormal clearance of immune complexes from the circulation of patients with primary sclerosing cholangitis. Gastroenterology 1985;88:166-70. 


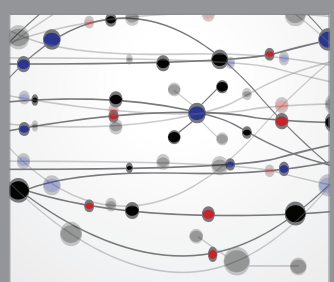

The Scientific World Journal
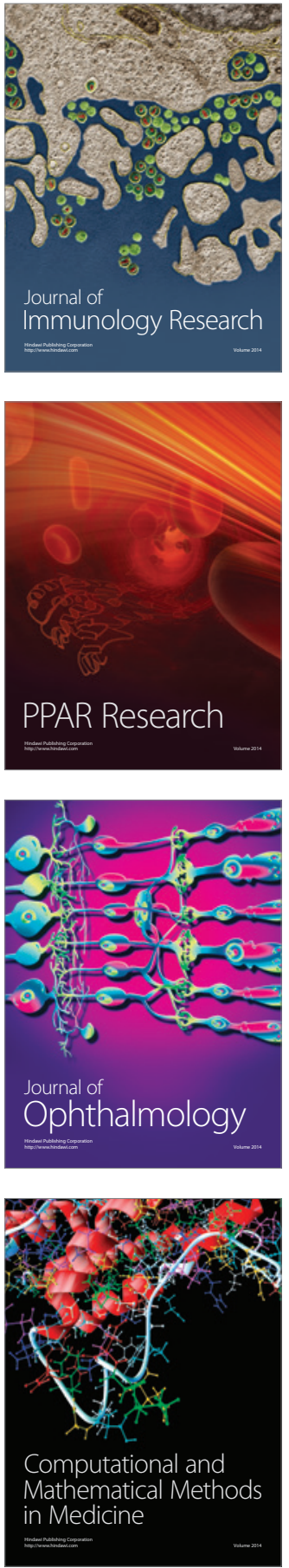

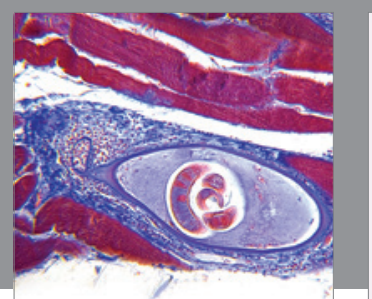

Gastroenterology Research and Practice

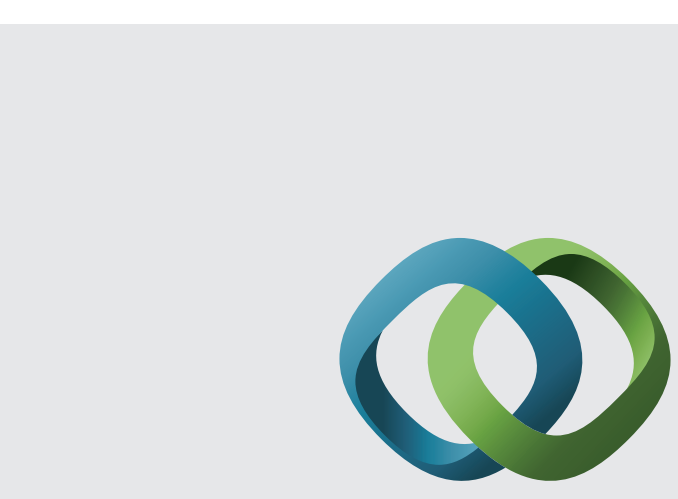

\section{Hindawi}

Submit your manuscripts at

http://www.hindawi.com
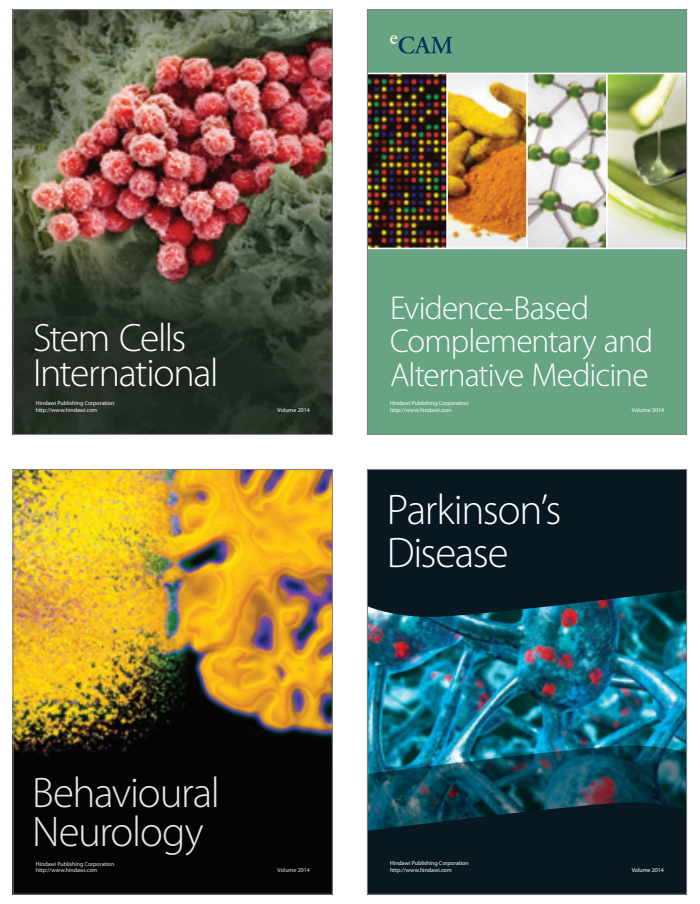
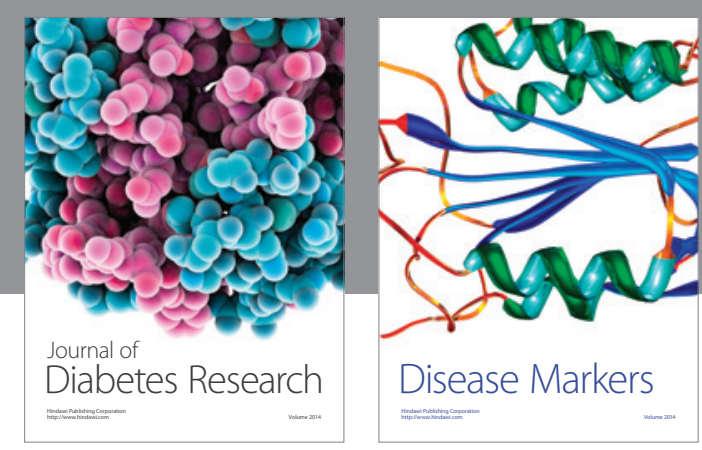

Disease Markers
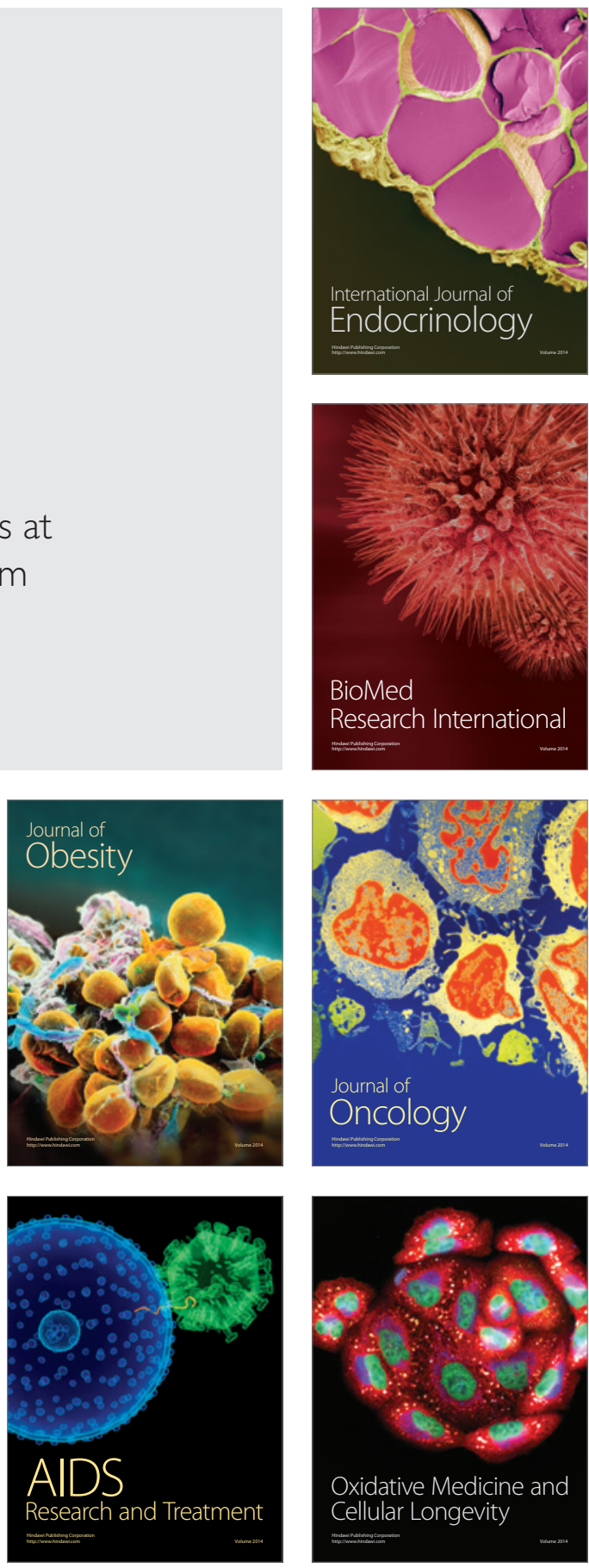